\title{
Distorted Time and Chaotic Narrative in Kazuo Ishiguro's The Unconsoled
}

\author{
Shu-Yuan Chang ${ }^{1, *}$, Hsu-Hui Cheng ${ }^{2}$ \\ ${ }^{1}$ School of Foreign Languages, Zhaoqing University, Zhaoqing 526061, China \\ ${ }^{2}$ School of Environmental and Chemical Engineering, Zhaoqing University, Zhaoqing 526061, China \\ *Corresponding author. Email: 2145632932@qq.com
}

\begin{abstract}
A feeling of surreality is what readers experience in Kazuo Ishiguro's The Unconsoled. Ishiguro does noticeable experiments with time, space, and perception related to postmodernism. By Kafkaesque experiment, Ishiguro unfolds Ryder's narrative about his four-day tour in an unspecified time and space. The inconsequentiality and the inconsistency which result from the temporal disorder and the non-linear narrative characterizes The Unconsoled as a postmodern novel. Besides the theme of memory, Ishiguro applies an illogical narrative to manage temporal dislocation and emotional estrangement in The Unconsoled. This article analyzes how Kazuo Ishiguro, by distorting temporal and spatial structures, creates a new narrative to present Ryder's labyrinth-like life which makes the novel a dream-like text.
\end{abstract}

Keywords: Surreality, Time and space, Kafkaesque experiment, Memory, Narrative, Dream-like text

\section{INTRODUCTION}

U. K. Heise suggests that "recent developments in science, technology, media, mode of production and social interaction help to explain the formal experiments postmodern novelists undertake, postmodern novels in their turn help to create the cultural lenses through which we perceive and interpret social and technological developments" [1]. Time and space give us a framework to understand various cultural developments in different eras. Human beings' perceptive to the world can be traced from contemporary narratives. The shift of time is inevitably revealed in those narratives as readers can find in The Unconsoled in which Ishiguro creates a complex and timeless atmosphere and through which an increasing change is perceived in the tensions between the "the immediacy of here and now, our physical location in space and time and the sorts of experiences, actions, events and whole worlds in which we can partake at a distance" [2]. The continuity of time and space becomes very problematic in The Unconsoled which forces readers to rethink the changes and meanings of both in present times.

\section{THE PLAY OF TIME}

\subsection{Distorted Time}

When reading The Unconsoled, readers soon find out how strange time and space are in the novel. It seems to be prolonged as if those happenings took place in one's dream. Ryder, an internationally famous pianist, checks into a hotel in an unnamed European city in which he will give a recital on Thursday night. It is for the first time he visits this foreign city, yet the place and the people he meets in the city seem familiar to him but he cannot remember who they are. He continually meets the citizens and is expected to squeeze a little time from his busy schedule to do them small favors, yet he never makes sure whether he really has a copy of this schedule. His reputation gives hope to the elites of the city who for that reason expect Ryder to solve their city crisis - the lack of soul of their hometown music. Ryder is always forced to put aside the thing he is doing reluctantly and does someone a favor. However, he always forgets his promises when subsequent requests come, and then forgets them as well.

In this over five hundred-page novel, Ishiguro tries to present Ryder's mind and life through so-called dreamnarrative which constantly frustrates readers by anachronism and digressions. By this narrative technique, Ishiguro shows his attempt on the departure from the polished tightly structured narrative of his earlier works.

\subsection{Ryder's Memory and Postmodern Novel}

The break-away time-space is directly reflected in 
Ryder's presentation of a world that becomes more chaotic and confusing to readers. Ryder, the forgetful first-person narrator, seems not so involved with his own life that makes The Unconsoled more difficult for readers to understand. Ryder "has almost no long-term memory. He can barely impose a minimal coherence on the events of the previous hours" [3]. Ryder's mind-shattering confusions soon lead readers into a fictional world where the time and space become inconsequential.

The ostentatious play with time and space creates a prolonged anxious dream and a hallucinatory exaggeration of the time bind. Ryder seems to live in a perpetual present without an identifiable past, but he seems to have no trouble to such situation except when he meets someone or something that might remind him some pieces of fragmentary memory. Surprisingly, Ryder shows no confusion or perplexity to his forgetfulness or his past.

The concept of lineal temporal succession, as the principal medium of narrative meaning, is challenged by many modernist novels which foreground the individual psychological time by simultaneity of different perspectives and moments in time. The storyline can be gradually reconstructed from the narrations of several narrators. The voice or the perspective of the narrators is more important than the temporal succession. The narrative time in The Unconsoled is not a psychological one because the unfolding of the story is not based on the flow of Ryder's memory or consciousness. Furthermore, Ryder's encounters in the unnamed city suggest that the time flow is impossible to be a realistic time.

Modernist writers "reinvented narrative structures so as to explore the flow of memory, duration and expectation in human consciousness" and postmodernist writers "design narrative forms that deliberately make temporal progression difficult or impossible to conceive" [1]. In other words, modernist novels generate a psychological temporality that transcends the mechanical time. The postmodern narrative logic is unable to be "justified in terms of the psychology of the human mind [1]. Postmodernist narrative time is detached from any specific human observer and is not used to represent any temporality except that in the text.

The twisted time and space puzzle readers whenever Ryder recalls his fragmentary memory or encounters someone. V. Passaro says, The Unconsoled 'doesn't progress, and won't; what it does do is twist, and the ultimate effect is of an intricate, thick braid, like a ship's line, stronger than sum of its parts, a rope wound together form strands of dreaminess, dislocation and loss" [4]. With the advanced technologies, human beings now live in a speed-up temporal experience. The time concept extended from the end of history becomes a distinguished trait in postmodern culture and therefore characterizes the postmodernist novels.

\section{DREAM-LIKE TEXT}

Ishiguro's illogical narrative makes The Unconsoled a distinguish style of narrative different from his previous novels. What Ryder narrates confuses readers because certain things beyond Ryder's ability to tell. Accordingly, the narrated reality Ryder offers might be from his imagination. Ishiguro applies Kafkaesque experiment in The Unconsoled which gives an effect of "seasickness at sea" because the whole story narrated by Ryder is difficult for readers to grasp certainty. Through Kafkaesque experiment, time in Ryder's narrative becomes twisted instead linear. The bizarre time and space places readers in a dream-like world which is full of disorienting and surreal distortion.

\subsection{Multiple Points of View}

The Unconsoled serves as an understanding of postmodern experiment with narrative temporality and cultural implications. The novel is told by Ryder, yet who "is no ordinary first-person narrator. He is not even an ordinary unreliable first-person narrator" [6]. Ryder seems to suffer from the problem of an inexplicable forgetfulness, and his narrative soon grows more chaotic and arbitrary with the unfolding of his visit in the city. Ryder's narration about his encounters in the city make readers unable to determine whether those happenings belong to the citizens or actually belong to Ryder himself. Ryder has trouble in recollecting his memory and personal history; however, he seems to be endowed with unusual extrasensory perceptions. Even though he is absent in some certain occasions, he has no difficulty overhearing conversations, having knowledge of other people's actions, and easily penetrating to the memories and thoughts of other people.

Contradictions of points of view are revealed in Ryder's narrative about the stories of other characters. When he tells the stories of other characters, he turns into an observer and a witness. Ryder is provided with some superman powers of observation which endows his "first-person narrative with multiple points of view" [6]. In other words, Ryder's narration “is refracted through what can only be called an omniscient/limited first/third-person point of view, and resists easy focalization. Ryder is not dreaming within his life; he is living within a dream. Whose dream it is, is not clear" [7]. He can elaborate the thoughts of the other characters even though he is absent at those occasions. In Chapter 5, Ryder meets Stephan and visits Miss Collins together. Ryder remains outside, but he can precisely describe the interior of Miss Collins's house and the dialogue between the two speakers. Later Ryder declines Stephan's request of listening to his piano practice. Ryder narrates Stephan's disappointment from a limited firstperson point of view. Then Ryder regains his omniscient point of view when narrating the event happened on 
Stephan's mother's birthday. Ryder has no trouble describing Stephan's mind and feeling toward his parents that they "were conspiring together against him" [8]. Stephan soon finds his performance disappoints his parents again because neither of his parents is looking at him. Unless this psychological reality belongs to Ryder himself; otherwise, as a first-person narrator, it is impossible for Ryder to see through Stephan's mind. When readers are given access to the thought of Stephan, readers speak not of omniscience but of limited point of view. At this moment, Ryder's subjectivity seems to turn into the character Stephan.

\subsection{Digression and Sense of Eccentricity}

Because of the chaotic narrative, B. Lewis argues that Ishiguro's The Unconsoled tries “to make some sense of its own decentredness and dismemberment, and its revolt against Aristotelian notions of unity" [7]. Every time the story is going to advance, "Ishiguro veers off in another indirection" and readers are "lost in maddening digression after maddening digression" [11]. Furthermore, these digressions feature a sense of eccentricity. All the events happen illogically. Such dream-like features occur again and again and undermine the logic and stability of the narrative of the whole novel.

Ryder's memory is unraveled in the digression of each encounter, but his narrative structure is different from Ishiguro's previous narrators. Ryder's uncertainty of his memory parallels the unhappy lives of other characters. He is constantly led from one strange place to another and does one senseless favor after another. Time and space is distorted as one peculiar event follows another which composes the chaotic narrative in The Unconsoled. The dream-like distortions of events, time and space in the novel show an illogical narrative of The Unconsoled. Ishiguro brings impossibility at every turn in Ryder's encounter which prevents readers from meaningfully speaking of the temporal base line or temporal orientation on the narrated events.

Ishiguro substitutes characters' past for Ryder's and this narrative technique should not be regarded as the psychological realism in modernist novels. The memories and perceptions of several different characters are juxtaposed, and in the end a coherent external reality ultimately emerges from the juxtaposition simultaneously. However, in The Unconsoled, whichever perspective it is, all the narratives are narrated by Ryder. Ryder can "turn certain characters into people from his past" [11] and "through the use of doubles" [5], readers reconstruct Ryder's obscure past. These doubles, such as Stephan and Boris, function as a catalyst to make Ryder remember his forgotten past, or, in a sense, forget his remembering past.

Through the strategy of substituting characters' past, Ishiguro presents Ryder's original family situation at different stages of his life. Clearly, the "family matters" that Ryder deals with in the relationship between Gustav and his daughter Sophie not only mirror his relationship with Boris but also echoes that with his hateful father. In addition, the Hoffman-Christine [Hoffman's wife] relationship and the Brodsky-Miss Collins one reveal the problems of miscommunication and dysfunctional family in the Ryder-Sophie relationship. Therefore, in the digressions of other characters' stories, Ryder meets himself at every turn in characters whose painful relationships refract his own traumatic past.

\subsection{Ishiguro's New Law to Narrative}

If readers think the hero in Stephan's story is actually Ryder himself, so he can tell the psychological reality of Stephan, it would become difficult to explain the constant shift of perspectives in the novel. Ryder describes that "Stephan's first feeling had been one of sheer terror" for the fear of ruining his mother's good mood [9]. The shift of narrative perspectives features Ryder as an "omniscient first-person narrator" [6]. Ryder's description of the scene in which Stephan is alone with his mother is regarded from the perspective of an omniscient narrator. Soon, Ryder's perspective shifts back to a limited first-person narrator as he narrates Stephan's return to his collage after his mother's birthday. Ryder seems ready to share his unlimited knowledge with readers all the time- - he knows every aspect about the tense relationship in Stephan's family. Ryder's telling of how Stephan gets along with his mother makes readers associate Ryder's relationship with his own mother. Readers are encouraged to think of the possibility that this lukewarm mother-son relationship between Stephan and his mother is in fact the portrayal of the relationship between Ryder and his own mother.

H. S. Nielsen argues that the first-person fiction is more like an autobiography because the narrator in the fiction narrates something which exists independently of what he narrates. Ryder can clearly tell other characters' minds and feelings from a perspective as an omniscient first-person narrator and sometimes can tell happenings as an omniscient third-person narrator. All of the mentioned features in Ryder's narrative transgress a "mimetic model of first-person narrative fiction in which the narrator is believed to possess the same limits, possibilities, and techniques at the disposal of an author of a traditional autobiography" [9]. M. Petry also suggests that it is "The 'impossibility' of the narrative perspective of the novel underscores the strangeness of its fictional world" [6]. The impossibility illustrates Ishiguro's attempt to confuse reader by ruling the world of The Unconsoled with new laws.

In his interview with D. O. Krider, Ishiguro explains the impossibility of the narrative perspective, Mr. Ryder can turn certain characters into people from his past, and bend and twist the whole world around into being some 
big expression of his feelings and emotions. Instead of using the more conventional methods like flashbacks, where you just learn about somebody's life from this point to that point, here, I thought, you could do it in a very different way, where someone apparently stumbles into this landscape in which everything is an expression of his past and his fears for the future" [10].

The place of an omniscient writer is replaced by Ryder, who can express his lack of parental love through telling Stephan's unhappy childhood. The world around him is twisted so as to reveal his feeling and emotions. When there is no primary character through whom the narration is focalized, readers usually get lost. Ryder, a primary character yet also an unusual first-person narrator, tells stories with different narrative voices which constantly lead readers astray. Ishiguro's illogical narrative confuses yet also forces readers to conjecture Ryder's past from the stories he tells from his shifting points of view.

\section{CONCLUSION}

The chaos and incoherence in Ryder's narrative presents that the development of telecommunication contributes to the attention of individuals and groups on "a rapid succession of micro-events and thereby makes it more difficult to envision even the short-term past or future" [1]. The constant distorted time and space in the novel can be regarded as a disguise of the accelerated temporal rhythms of contemporary society. At the turn of twentieth century, the circle of production and consumption has appeared as obstacle that impedes the long-term construction of time. The more exact the time people can tell, the more the pressure people feel from the lack of time. The temporal organization breaks down and causes the subject to lose its capacity organize its past and future into coherent experiences. Ryder's narrative reveals lots of illogical, inconsequential events in which both time and space become bizarre. It suggests that without the ability to manage the intervals of time, an individual will meet perpetual time deficit and time anxiety as Ryder does.

When reading a postmodern novel, readers cannot "determine with certainty if any of the scenes are supposed to form part of the narrated reality, or whether they are to be understood as figments of the narrator's imagination or simple exercises of style" [1]. Heise's analysis indicates that it is difficult to grasp the temporal progression in postmodernist novels due to its impossible temporal structure and the illogical narrative. Ishiguro's illogical narrative creates a surreal world in which Ryder's forgetfulness forms the development of the story. Adelman's "the doubles" and Lewis's omniscient/limited first-/third-person point of view explain how Ryder reveals his past through stories of other characters. Ryder's vague awareness of those digression moments and places adds his memories a quality of an evanescence. The Unconsoled, which prompts reactions like boredom and chaos, is not considered as successful as Ishiguro's previous works; however, Ishiguro's experimental narrative creates a new style to deal with the protagonist's past as well as the memory theme.

\section{REFERENCES}

[1] U. K. Heise, Chronoschisms: Time, Narrative, and Postmodernism. Cambridge UP, 1997.

[2] R. Friedland, and Boden D, Ed. NowHere: Space, Time, and Modernity. U of Chicago P, 1994.

[3] R. Rorty, Consolation Prize. Rev. of The Unconsoled, by Kazuo Ishiguro. Village Voice Literary supplement 1995 (40. 41): 13.

[4] V. Passaro, New Flash from an Old Isle-The Unconsoled by Kazuo Ishiguro. Rev. of The Unconsoled. Kazuo Ishiguro. Harper's Magazine 1995 (291): 71-75.

[5] G. Adelman, Doubles on the rocks: Ishiguro's The Unconsoled. Critique 2001 (42. 2): 166-179.

[6] M. Petry, Narrative of Memory and Identity: The Novels of Kazuo Ishiguro. Frankfurt Berlin: Peter Lang, 1999.

[7] B. Lewis, Kazuo Ishiguro. Manchester: Manchester UP, 2000.

[8] K. Ishiguro, The Unconsoled. London: Faber \& Faber, 1995.

[9] H. S. Nielsen, The impersonal voice in first-person narrative fiction. Narrative 2004 (12. 2): 133-150.

[10] D. O. Krider, Rooted in a small space: an interview with Kazuo Ishiguro. Kenyon Review 1998 (20. 2): 149-154.

[11] G. Lawson, Musical and Narrative Chaos. Rev. of The Unconsoled, by Kazuo Ishiguro. Maclean's 1995 (108. 21): 70-71. 